\title{
Diversification of Hosiery Production to Cotton Blended Knitwear
}

\author{
Nisha Arya* \\ Department of Textiles and Apparel Designing, COHS, CCSHAU, Hisar-125004, Haryana, India \\ *Corresponding author
}

\begin{abstract}
A B S T R A C T
Knitted fabrics are much in demand due to their snug fitting, stretchability, easy care, soft handle and wrinkle resistant quality suitable for sportswear and other casual wearing apparels. In the present situation, to meet the raw material crisis of natural fibres and to provide the textile industry with a low priced substitute of natural fibres; blending of

manmade fibres are essential. Cotton is the best-suited fibre for blending with manmade fibres. The present work on weft knitted p/c blended knitted fabrics was done to meet the raw material crisis of natural fibres and to provide a low priced substitute of natural fibre to the textile industry. The blending and spinning of two fibres (cotton and polyester) was done by batch method and on open end spinning system with $40^{\mathrm{s}}$ respectively. Plain weft knitted fabric was produced from the blended yarns on circular weft knitting machine with 26-inch diameter. While comparing the cost of $\mathrm{P} / \mathrm{C}$ blend with cotton fibre /yarn/fabric, it was found that 50:50 P/C blended yarn as well as fabric cost lesser as compared to 100 percent cotton. Effect of wear on constructional properties of weft knitted Polyester-cotton blended fabric was studied after different levels of wear and washing. It was concluded that constructional properties changed more after 10 washings and wears. Fabric count increased significantly after different level of wear. Fabric thickness and weight also increased significantly after ten wears but after that thickness and weight decreased. Variability was maximum in case of thickness $(\mathrm{CV}=4.25)$ and minimum for fabric courses $(\mathrm{CV}=1.34)$. Being the producer of cotton, the rural masses can take up or adopt knitting as a income generating source, to set up a small scale enterprise.
\end{abstract}

Keywords

Knitting,

Constructional,

Blending, Fabric

Count, Variability.

Article Info

Accepted:

04 October 2017

Available Online:

10 December 2017

\section{Introduction}

Textile consumer is generally concerned with high performance, low cost and aesthetic appearance of the fabrics. Blending, as applied to textiles, can be defined as the intimate mixture of two or more dissimilar fibres. Most of the natural fibres lack certain desirable properties, and the manmade fibres when properly applied in blends help to get these properties. Blending is also practiced for reasons of economy of production and shortage of cotton (Mansour et al., 1998). Blending of fibrous materials is a technique to achieve and satisfy both the manufacture and consumer's requirements.

Now a day, knitted fabrics are much in demand due to their snug fitting, stretchability, easy care, soft handle and wrinkle resistant quality suitable for sportswear and other casual wearing apparels (Strohle and Guruprasad, 2002). Indian cotton knitwear has wide acceptability in the world market because cotton is enjoying a big "ecological bonus", as a natural fibre. Cotton 
is distinguished by the following properties: good absorption of fluids, biodegradability, breathing activity, drapability, easily sterilized, heat -resistant, high wet strength, insulating properties, non-allergenic, non irritant, renewable resources, softness and water retention capacity. But, to meet the raw material crisis of natural fibres and to provide the textile industry with a low priced substitute of that natural fibre and thus meeting the demands of increasing population, blending of manmade fibres and natural fibres is essential. In a country like India, with extremes of temperature and humidity, garments made from natural fibres in cotton or blends of manmade and natural fibres are certainly preferred to pure synthetics for reason of environment and health. Cotton is the best suited fibre for blending with manmade fibres. Punjab's hosiery Industry, a traditionally seasonal business, has transformed into an all -season industry due to diversification. From woolen knitwear, the business has moved on to cotton and blended knitwear (Chawla, 2011).The expansion of the industry to round-the-year has brought in a huge spinning industry (cotton and man-made fibers) and led to development of other industry.

The present work on weft knitted p/c blended knitted fabrics was done to meet the raw material crisis of natural fibres and to provide a low priced substitute of natural fibre to the textile industry. Being the producer of cotton, the rural masses can take up or adopt knitting as an income generating source, to set up a small scale enterprise.

\section{Technical plan}

The proposed study was undertaken with a view to produce cotton-polyester blended knits (being eco-friendly), which would be within the accessibility of common consumers.
The raw material selected for the study includes cotton and polyester. The blending and spinning of two fibres (cotton and polyester) was done by batch method and on open end spinning system with $40^{\mathrm{s}}$ respectively.

Plain weft knitted fabric was produced from the blended yarns on circular weft knitting machine with 26-inch diameter. T-shirts were knitted from 100 percent cotton, 100 percent polyester and 50:50 p/c blends. Comparison of blended yarn and fabric was done with 100 percent cotton and polyester to analyze the cost of individual T-shirts.50:50 P/C blend was identified as the best proportion by expert and consumers for T-shirt (again identified by the same group). Hundred T-shirts (identified by the experts and consumers) were knitted out of 50:50 polyester-cotton blends. Standard measurements and method of drafting were taken from specifications approved by the Government Hosiery Standardization Centre, Ludhiana (Punjab). Sixty respondents from rural areas were selected randomly for trial of the knitted garments.

Each of the respondents wore each T-shirt eight hours a day for three consecutive days. This time-period was considered as one wear. The garments were given to the respondents for 10 wears, 15 wears and 20 wear; comprising total 30, 45 and 60 days, respectively.

The garments were laundered following the modified procedures of AATCC standards (No.88A-1964T) and BIS standards (IS: 1313:1950) using 2 per cent neutral detergent solution with material liquor ratio 1:20 at temperature 35 to $37{ }^{\circ} \mathrm{C}$ for 5-7 minutes. The laundering cycle was carried out for 10,15 and 20 wears. The constructional and dimensional properties were determined by following the standard procedures. 


\section{Results and Discussion}

This section includes the cost estimation of yarn preparation and cost estimation of knitted t-shirts. The detailed data on cost analysis are presented in Table 1 and 2. This section also includes the information regarding the constructional (fabric count wales and courses, thickness and weight) and fabric dimensional properties (loop length stitch density, tightness factor, loop shape factor, bulk and area shrinkage) of the weft knitted 50:50 p/c blended fabric after testing at different levels of wear and washing (Table 3 and 4).

\section{Cost estimation of yarn preparation}

The cost of raw material was calculated on the basis of 50:50 $\mathrm{P} / \mathrm{C}$ proportion, 100 per cent polyester and 100 per cent cotton with the cost of polyester Rs. 40 and cotton Rs. 45 per $\mathrm{kg}$. The price for raw material of 50:50 $\mathrm{P} / \mathrm{C}$ blend comes out to be Rs.42.50 $(20+22.50)$. Spinning charges were taken as Rs.22 per kg. Ten per cent waste of the cost of raw material and 18 per cent interest for minimum 30 days was taken into account. Packing charges were taken at the rate of 1.50 per $\mathrm{kg}$. The cost of yarn was found to be Rs.70.87 for blended yarn, Rs.68.09 for 100 per cent polyester yarn and Rs.73.66 for 100 per cent cotton yarn. On this cost, 18 per cent and 15 per cent excise duty, surcharge and transport charges Rs.1 was also added to the cost of the yarn. The actual cost of the yarn comes out to be Rs.86.53 for blended yarn, Rs.83.17 for 100 per cent polyester yarn and Rs.89.89 for 100 per cent cotton yarn.

\section{Cost estimation of knitted T-shirts}

Cost estimation of blended T-shirts and 100 per cent polyester and cotton was estimated on the basis of its weight (Table 2). The cost of one kilogram of yarn had been calculated.
On the basis of weight of the T-shirts, the cost of the yarn of the T-shirts was found to be Rs.16.87, 13.30 and 18.42 for $50: 50 \mathrm{P} / \mathrm{C}$ blended, 100 per cent polyester and 100 per cent cotton, respectively.

The wages for knitting and stitching were at the rate of Rs.12.50 per kg. Two per cent waste and 18 per cent interest was calculated on the basis of cost of the yarn. Rs.0.25 taken as packing cost and Rs.0.10 for transport charges for each $\mathrm{T}$-shirt was taken into account. The total cost of T-shirts was recorded as 22.65, 18.10 and 24.51 for blended, 100 per cent polyester and 100 per cent cotton, respectively.

On cost estimation, it was found that total cost of blended T-shirts was lesser (Rs.22.65) as compared to 100 per cent cotton (Rs.24.51) and polyester (Rs.18.10) T-shirts.

\section{Analysis of fabric constructional parameters}

It is evident that after 10 wears number of wales per $\mathrm{cm}$-increased from16 to 16.4 as compared to controlled fabric. After 15 wears, number of wales again increased (16.8), while it remained same i.e., 16.8 thereafter (20 wears). The results were significant with $\mathrm{CD}$ 0.49 . Data elucidated that number of courses increased after 10 wears from 17.6 to 18.8 per $\mathrm{cm}$ as compared to controlled fabric but after that it remained same (i.e. after 15 and 20 wears).The difference was significant with C.D. 0.22 .

Data on thickness revealed that thickness of the fabric increased significantly $(0.57 \mathrm{~mm})$ up to 10 wears as compared to controlled fabric $(0.54 \mathrm{~mm})$. After analyzing the thickness at different levels, it was observed that fabric thickness started decreasing after ten wears. It was $0.55 \mathrm{~mm}$ after 15 wears and $0.50 \mathrm{~mm}$ after 20 wears. 
Table.1 Cost (Rs. $/ \mathrm{kg}$ ) estimations of $40^{\mathrm{S}}$ yarn prepared on O.E. mechanism

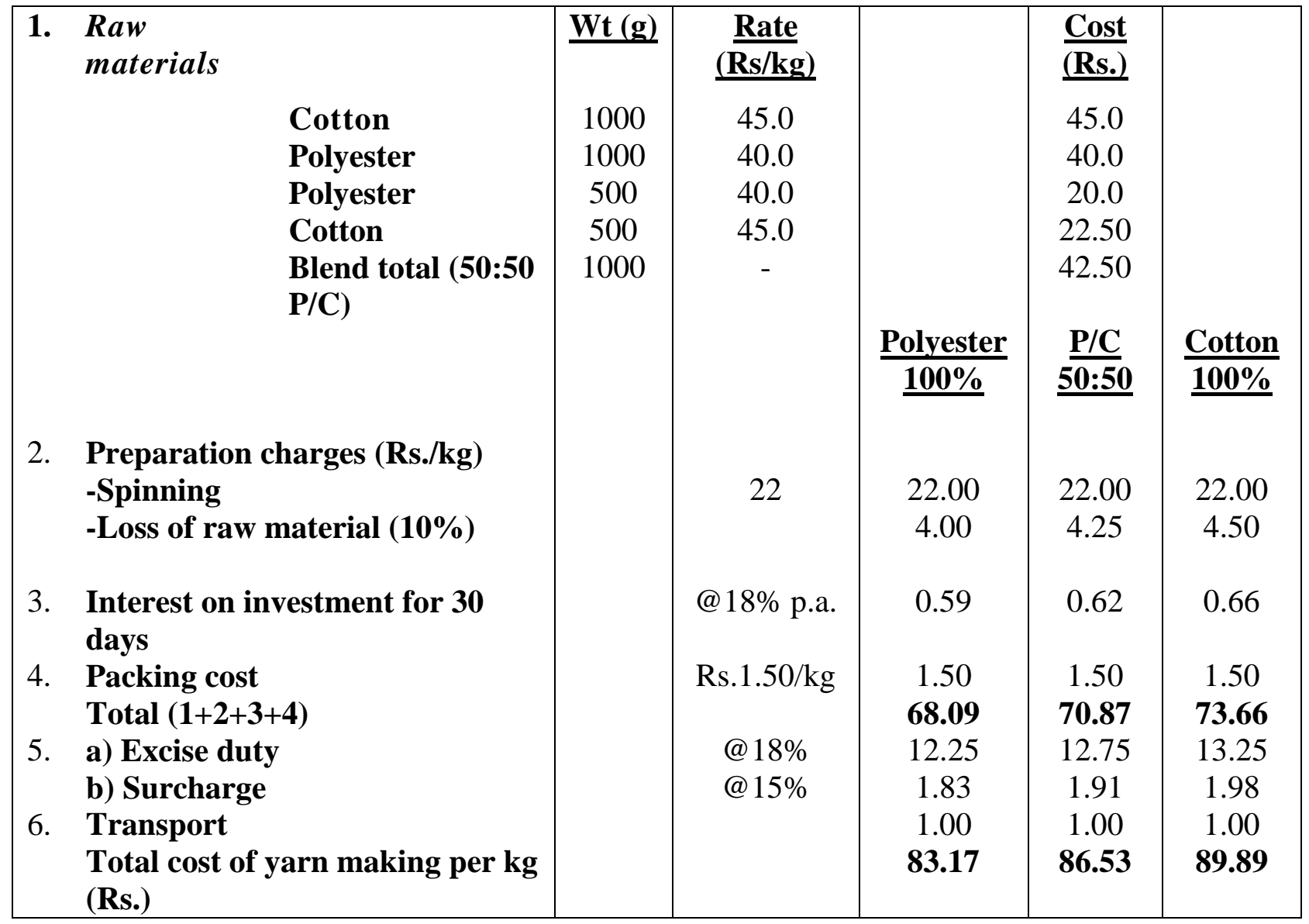

Table.2 Cost estimation of $40^{\mathrm{S}}$ count yarn of O.E. knitted T-shirts

\begin{tabular}{lccc}
\hline Charges & \multicolumn{3}{c}{ Cost estimation of T-shirt for } \\
\cline { 2 - 4 } & $\mathbf{1 0 0 \%}$ polyester & Blended yarn & $\mathbf{1 0 0 \%}$ cotton \\
\hline Weight of T-shirt & $160 \mathrm{~g}$ & $195 \mathrm{~g}$ & $205 \mathrm{~g}$ \\
Cost of the yarns (Rs.) & 13.30 & 16.87 & 18.42 \\
Wages for knitting @ Rs.12.50 & 2.00 & 2.43 & 2.56 \\
per kg & & & \\
Stitching charges @Rs.12.50 & 2.00 & 2.43 & 2.56 \\
per kg & & & \\
Losses @ 2\% & 0.26 & 0.33 & 0.36 \\
Interest on capital @ 18\% for 30 & 0.19 & 0.24 & 0.26 \\
days & & & 0.25 \\
Packing cost & 0.25 & 0.25 & 0.10 \\
Transport Cost/piece & 0.10 & 0.10 & $\mathbf{2 4 . 5 1}$ \\
& & & $\mathbf{2 2 . 6 5}$ \\
Total cost per T-shirt & $\mathbf{1 8 . 1 0}$ &
\end{tabular}


Table.3 Effect of wear on constructional properties of weft knitted fabric with 50:50 P/C blend

\begin{tabular}{lllllllll}
\hline & & \multicolumn{2}{l}{ Levels of wear } & & & & \\
\cline { 2 - 7 } & $\begin{array}{l}\text { Fabric } \\
\text { properties }\end{array}$ & $\begin{array}{l}\text { Controlled } \\
\text { fabric }\end{array}$ & $\begin{array}{l}\text { After 10 } \\
\text { wears }\end{array}$ & $\begin{array}{l}\text { After } \\
\text { wears }\end{array}$ & $\begin{array}{l}\text { After } \\
\text { wears }\end{array}$ & $\begin{array}{l}\text { CD } \\
(\boldsymbol{\alpha}=\mathbf{0 . 0 5})\end{array}$ & $\begin{array}{l}\text { CV } \\
(\boldsymbol{\%})\end{array}$ \\
\hline 1. & Fabric count & & & & & & \\
& Wales & 16.0 & 16.4 & 16.8 & 16.8 & 0.49 & 3.26 \\
& Courses & 17.6 & 18.8 & 18.8 & 18.8 & 0.22 & 1.34 \\
2. & Thickness $(\mathrm{mm})$ & 0.54 & 0.57 & 0.55 & 0.50 & 0.02 & 4.25 \\
3. & Weight $\left(\mathrm{g} / \mathrm{m}^{2}\right)$ & 191.6 & 212.6 & 210.8 & 205.0 & 4.90 & 2.63 \\
\hline
\end{tabular}

Table.4 Effect of wear on dimensional properties of weft knitted fabric with 50:50 P/C blend

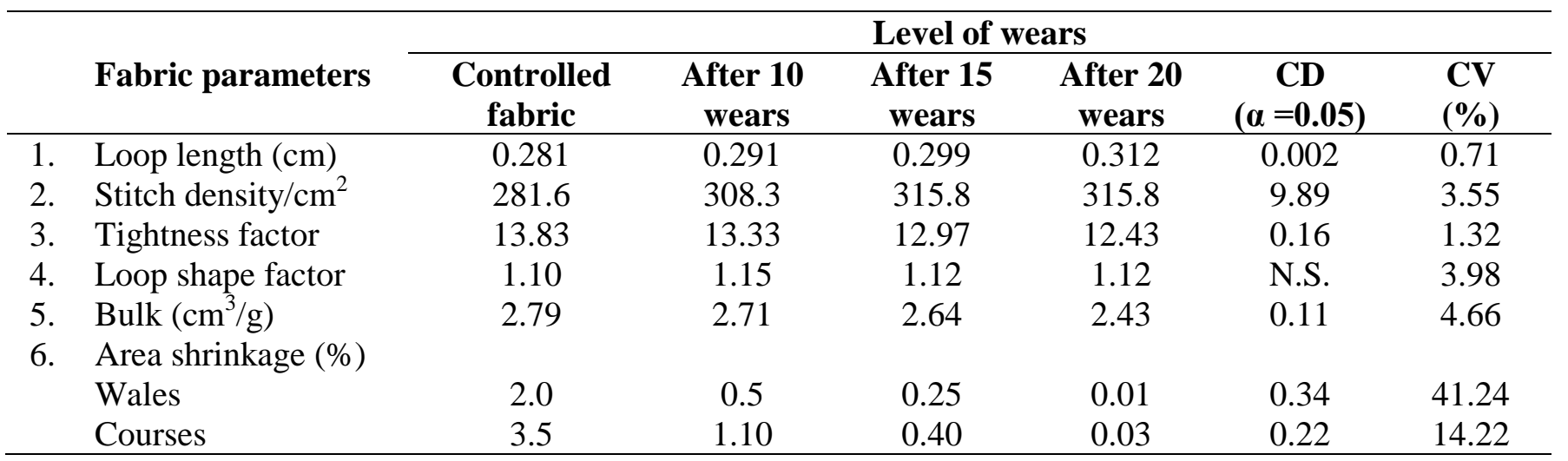

The weight of the fabric studied for the controlled fabric after 10, 15 and 20 wears is presented in Table 1. It is evident from the results that the weight of the controlled fabric was $191.6 \mathrm{~g} / \mathrm{m}^{2}$. But after 10 wears, it increased to $212.6 \mathrm{~g} / \mathrm{m}^{2}$ whereas it again decreased after 15 and 20 wears with a mean value of 210.8 $\mathrm{g} / \mathrm{m}^{2}$ and $205 \mathrm{~g} / \mathrm{m}^{2}$, respectively.

This increase and decrease in the weight might be due to its relation to fabric count and thickness, as thickness increased, weight also increased and as thickness decreased weight also decreased. Increase in weight and thickness after 10 wears might be due to shrinkage. After several launderings, the fabric become thin and lean, due to thinning of cotton. Hence, the weight and thickness decreased after 15 and 20 wears. The change in weight was significant with CD 4.90 .

\section{Analysis of fabric dimensional parameters}

It is evident from Table 2 that stitch length of controlled sample was $0.281 \mathrm{~mm}$ which increased after 10 wears, 15 wears and 20 wears with a mean value of $0.291 \mathrm{~mm}, 0.299 \mathrm{~mm}$ and $0.312 \mathrm{~mm}$, respectively.

This increase in loop length might be due to enlargement of loops after frequent washings and wears.

The data depicted that stitch density of the fabric increased after ten wears, while it remained same after fifteen and twenty wears.

It was found to be $308.3 \mathrm{~cm}^{2}$ after ten wears, $315.8 \mathrm{~cm}^{2}$ after fifteen and twenty wears as against $281.6 \mathrm{~cm}^{2}$ for controlled fabric. The increase in stitch density was significant with CD 9.89. Tightness factor decreased after ten, fifteen and twenty wears. Tightness factor was found to be $13.33,12.97$, and 12.43 after ten, fifteen and twenty wears, respectively, against controlled fabric (13.83). Tightness factor is inversely proportional to loop length; it decreased as the loop length increased. The results obtained were significant with CD 0.16.The findings of Sharma et al., (1992) also 
supported this study by reporting that in plain knitted fabrics made from OE yarns, increased stitch length reduced the tightness of the fabric.

Data revealed that LSF of the fabric after ten wears was more (1.15) when compared to controlled fabric with LSF value of 1.10 . It decreased after fifteen wears (1.12) and remained same after twenty wears.

The data presented in Table 2 show that fabric bulk was $2.79 \mathrm{~cm}^{3} / \mathrm{g}$ in case of controlled fabric which decreased after ten, fifteen and twenty wears from $2.71,2.64$ to $2.43 \mathrm{~cm}^{3} / \mathrm{g}$. The results obtained are significant with CD 0.11 .

It is evident from Table 2 that the area shrinkage of 50:50 P: C blend fabric decreased after increased wears and washings. It was found that 2.0 and 3.5 per cent area shrinkage was observed in wale and course wise direction, respectively, for controlled fabric whereas shrinkage was found only 0.5 per cent and 1.10 per cent after ten wears and 0.25 and 0.40 per cent after fifteen wears in wale and course wise direction, respectively. But no additional shrinkage was observed after twenty wears. According to Munshi et al., (1994) also P: C fabrics got stabilized after some launderings itself due to non-shrinkable nature of polyester fibres.

It is concluded that dimensional properties of weft knitted fabric with 50:50 P:C blend vary. Loop length stitch density, loop shape factor increased whereas tightness factor, bulk and area shrinkage decreased after different level of washing and wear. Maximum variability was observed in case of area shrinkage with $\mathrm{CV}_{\mathrm{W}}=41.24$ and $\mathrm{CV}_{\mathrm{C}}=14.22$ ) followed by bulk $(\mathrm{CV}=4.66), \mathrm{LSF}(\mathrm{CV}=3.98)$, and stitch density $(\mathrm{CV}=3.55)$. Loop length and tightness factor showed very low variability with $\mathrm{CV}=0.71$ and
1.32, respectively. As far as cost is concerned, comparison of blended T-shirts with those prepared with $100 \%$ cotton revealed that the former cost was found to be lesser. It is concluded that constructional properties changed more after 10 washings and wears. Fabric count increased after different level of wear. Fabric thickness and weight also increased after ten wears but after that thickness and weight decreased. Dimensional properties of weft knitted fabric with 50:50 P:C blend vary with level of wear i.e. loop length stitch density, loop shape factor increased whereas tightness factor, bulk and area shrinkage decreased after different level of washing and wear.

Hence, this is expected that the blend may emerge as a cheaper and a better substitute for pure cotton and this product will give a boon to the industry to produce low cost knits. This can be taken up as entrepreneur for supplementing the family income.

\section{References}

Ajmeri, J.R. and Ajmeri, C.J. (2001). Polyester leading the fibre market. Textile Magazine, 8: $48-50$.

Anonymous (2004) www.MSN Encarta-Fibre. Htm.

Mansour, S.A., Messiery, M.E., Ibrahim, s., Saad, M.A. and Hanafy, I. (1998). Triple yarn blending. The Indian Textile Journal, 5: 58.

Munshi, V.G., Pai, S.D., Ukidve, A.V. and Bhaskar, P. (1994). Studies on dimensional changes of fabrics due to washing. The Indian Textile Journal, 54: 62-64.

Sharma, N., Chandra, B. and Goel, P. (1992). Future of textiles. Indian Journal of Fibre and Textile Research, 18: 110-115.

Strohle, J. and Guruprasad, C.N. (2002). Open width processing of knit goods-challenges and solutions, Colourage, 10: 37-38.

\section{How to cite this article:}

Nisha Arya. 2017. Diversification of Hosiery Production to Cotton Blended Knitwear. Int.J.Curr.Microbiol.App.Sci. 6(12): 91-96. doi: https://doi.org/10.20546/ijcmas.2017.612.012 